\title{
Anti-angiogenic effect of total saponins of Rhizoma Dioscorea nipponica on collagen induced-arthritis in rats
}

\author{
XIU-JUN LIANG ${ }^{1 *}$, YA-CHUN GUO ${ }^{2 *}$, TONG-YOU SUN ${ }^{3}$, HONG-RU SONG $^{4}$ and YA-XIAN GAO ${ }^{4}$ \\ ${ }^{1}$ Basic Medical Institute; ${ }^{2}$ Department of Pathogen Biology, Chengde Medical University; \\ ${ }^{3}$ Center of Radiation and Chemotherapy, Chengde Central Hospital; ${ }^{4}$ Department of Immunology, \\ Chengde Medical University, Chengde, Hebei 067000, P.R. China
}

Received March 18, 2015; Accepted April 21, 2016

DOI: $10.3892 /$ etm.2016.3586

\begin{abstract}
Rheumatoid arthritis (RA) is a common chronic autoimmune and incurable disease. The aim of the present study was to investigate the therapeutic effect and mechanism of the total saponins of Rhizoma Dioscorea nipponica (TSRDN) in RA. A collagen induced-arthritis (CIA) rat model was established. CIA rats were randomly divided into three groups and lavaged with an equal volume of solvent (CIA group), TSRDN (25 mg/kg/day, RDN group) and tripterygium (TP; $12 \mathrm{mg} / \mathrm{kg} /$ day, TP group) for 21 days, respectively. Normal rats served as a control group. Hematoxylin-eosin (HE) staining was used to observe the histopathological injury of synovial tissues. The level of CD31, which used for marking and counting, micro vessel density (MVD) and the expression levels of vascular endothelial growth factor (VEGF) and signal transducer and activator of transcription 3 (STAT3) were detected by immunohistochemical analysis. Additionally, the DNA-binding activity of nuclear factor $-\kappa \mathrm{B}(\mathrm{NF}-\kappa \mathrm{B})$ was determined using an ELISA kit. HE staining showed obvious synovial hyperplasia, inflammatory cell infiltration, pannus formation, cartilage and bone erosion in the CIA group rats. In addition, compared with control group, the level of MVD, the expression of VEGF and STAT3, and the DNA-binding activity of NF- $\mathrm{B}$ were all increased in CIA group rat synovial tissue (all $\mathrm{P}<0.01$ ); however, TSRDN or tripterygium were able to inhibit these changes (all $\mathrm{P}<0.01)$. It was speculated that TSRDN may prevent angiogenesis by inhibiting the expression of STAT3
\end{abstract}

Correspondence to: $\mathrm{Dr}$ Hong-Ru Song, Department of Immunology, Chengde Medical University, Science and Office building, 1 Anyuan Road, Chengde, Hebei 067000, P.R. China E-mail: songhongru@163.com

*Contributed equally

Key words: total saponins of rhizoma dioscoreae nipponicae, rheumatoid arthritis, vascular endothelial growth factor, signal transducer and activator of transcription, nuclear factor- $\kappa \mathrm{B}$ and the DNA-binding activity of NF- $\mathrm{B}$ p 65 , thereby potentially improving CIA.

\section{Introduction}

Rheumatoid arthritis (RA) is a chronic autoimmune disease with pathological characteristics including synovitis, synovial hyperplasia, infiltration of inflammatory cell and formation of pannus $(1,2)$. RA has a population prevalence of $0.5-1 \%$ worldwide (3). RA has been associated with a range of risk factors, including genetics, smoking, environment, immune regulation and infectious agents (3). A variety of the molecular mechanisms on the occurrence and development of RA have been reported (4). In addition to inflammatory and immunological responses, increased angiogenesis has been considered play a vital role in the early pathological process of RA and sustains synovitis by producing proinflammatory cytokines and chemokines (5). Vascular endothelial growth factor (VEGF), as the most effective proangiogenic molecule, is highly expressed in RA synovial tissue (6). Moreover, several studies have been suggested that signal transducer and activator of transcription (STAT3) (7) and nuclear factor- $\kappa \mathrm{B}(\mathrm{NF}-\kappa \mathrm{B})(8)$ are associated with the pathogenesis of RA and have an important regulatory effect on angiogenesis $(9,10)$. Currently, a variety of approaches, such as thermotherapy, anti-inflammatory therapy and gene therapy, have been suggested to treat RA (11). However, in consideration of the effectiveness and side effects of drugs, it is essential to identify and develop novel therapies for RA.

The total saponins of Rhizoma Dioscorea nipponica (TSRDN), a traditional Chinese medicine (TCM) extracted from the roots of RDN, has been suggested to aid in dispelling wind, eliminating dampness, alleviating pain, promoting blood circulation and suppressing cough (12). Previous studies have indicated that TSRDN may be able to reduce levels of total cholesterol and serum glucose, as well as eliminate hydroxyl radicals $(13,14)$. A prior study showed that TSRDN may improve acute gouty arthritis by inhibiting the expression of inflammatory factors (15). However, it remains unclear whether TSRDN has a therapeutic effect on RA.

In the present study, a collagen-induced arthritis (CIA) rat model was established which had similar clinical and pathological features to human RA (16). The aim of the study was 
to investigate the role and therapeutic mechanism of TSRDN in RA by detecting the expression levels of CD31, VEGF,

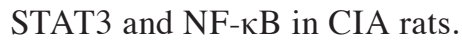

\section{Materials and methods}

Animal models. Approval from the Animal Ethics Committee of the Animal Laboratory Center of Chengde Medical University (Chengde, China) was obtained prior to using the animals for research. Healthy Wistar rats (age, 42 days; $n=168$; weight, $170 \pm 20 \mathrm{~g}$; half male and female) were provided by Vital River Laboratory Animal Technology Co. Ltd. (Beijing, China), and acclimatized to a natural day/night cycle and given ad libitum access to food and water at $21^{\circ} \mathrm{C}$ for a week before the trial.

Collagen induced-arthritis (CIA) rat model was established using the method described by Cremer et al (17). In brief, type II collagen emulsion was prepared by mixing bovine type II collagen (2 g/l; Sigma-Aldrich, St. Louis, $\mathrm{MO}, \mathrm{USA}$ ) in $0.05 \mathrm{M}$ acetic acid with an equal volume of complete Freund's adjuvant (Sigma-Aldrich). Subsequently, $10 \%$ chloral hydrate (Sigma-Aldrich) was used to anesthetize rats, then the rats were injected intradermally with type II collagen emulsion $(0.2 \mathrm{ml})$ into the back and tail roots of rats. The second immunisation was performed with the same dose of type II collagen emulsion after 7 days. Arthritis was evaluated by measuring the arthritis index (AI), according to the method described in a previous study (18). AI was measured by the joint swelling degree and the number of affected joints as following: 0, Normal joints; 1 , swelling slightly of toe joints; 2 , swelling of toe and digit joints; 3 , swelling of foot paw below the ankle joints; and 4, entire swelling of foot paw including ankle joints. AI was defined as the sum of scores of the limbs joint swelling level (total potential score of 16). Rat with an AI score of $\geq 4$ were considered to be a successful CIA model, while rats with AI $<4$ were excluded from the study.

Animal grouping, drug administration and sample collection. A total of $168 \mathrm{Wistar}$ rats were enrolled in our study. Of these, 32 rats were injected with physiological saline in an equal volume as blank control, and 136 rats underwent the establishment of CIA model. After the first immunization 0 , $10,20,30,40,50$ and 60 days, 8 rats were randomly selected to undergoing analysis of joint swelling and AI in the model rat and blank control groups, respectively. At 14 days after the first immunization, CIA model rats were randomly allocated into 3 groups ( $n=24$ per group) and lavaged with an equal volume of double distilled water (CIA group), TSRDN (25 mg/kg/day, RDN group) or tripterygium (12 mg/kg/day, TP group) for 21 days, respectively. TSRDN was provided by the Department of Traditional Chinese Medicine of Chengde Medical University and tripterygium was obtained from Huangshi Feiyun Pharmaceutical Co., Ltd. (Hubei, China). The rats in blank group were also lavaged with an equal volume of solvent for 21 days. Following the treatment periods, the rats were anesthetized with $10 \%$ chloral hydrate and sacrificed by cervical dislocation. The knee joint synovium were harvested for histopathological and immunohistochemical assessment, and nucleoproteins were extracted for detection of the DNA-binding activity of $\mathrm{NF}-\kappa \mathrm{B}$ p65.

Histopathological assessment. Specimens were fixed in $4 \%$ paraformaldehyde solution for $24 \mathrm{~h}$, then paraffin-embedded tissue samples were cut into $5-\mu \mathrm{m}$ sections. Sections were incubated for $4 \mathrm{~h}$ for deparaffinization at $65^{\circ} \mathrm{C}$ and dehydrated with gradient ethanol. Subsequently, the sections were stained with hematoxylin (Sigma-Aldrich) for $5 \mathrm{~min}$. Following differentiation in $1 \%$ hydrochloric acid alcohol for $2 \mathrm{sec}$, the sections were incubated in ammonia water for $2 \mathrm{~min}$, and stained with eosin for $1 \mathrm{~min}$. Ultimately, the sections were dehydrated, cleared and mounted with neutral resin. Light microscopy (Olympus Corporation, Tokyo, Japan) was used to observe the sections.

Immunohistochemical analysis of CD31, VEGF and STAT3. The sections were incubated with $3 \% \mathrm{H}_{2} \mathrm{O}_{2}$ to block the endogenous peroxidase. An antigen retrieval step in $10 \mathrm{mM}$ citrate buffer ( $\mathrm{pH}$ 6.0) for $10 \mathrm{~min}$ was performed. Sections were blocked using normal goat serum (Zhongshan Golden Bridge Biotechnology Co., Ltd., Beijing, China) at $37^{\circ} \mathrm{C}$ for $30 \mathrm{~min}$, then incubated with rabbit anti-rat CD31 (1:50; cat. no. sc-1506; Santa Cruz Biotechnology, Inc., Santa Cruz, CA, USA), VEGF (1:50; cat. no. RB-222-P0; Thermo Fisher Scientific, Inc., Waltham, MA, USA) and STAT3 antibody (1:50; cat. no. 1122-1; Epitomics, Inc., Burlingame, CA, USA) for $30 \mathrm{~min}$, respectively, and washed with phosphate-buffered saline (PBS). Subsequently, the sections were incubated with goat anti-rabbit secondary antibody (1:200; cat. no. ZB-2301; Zhongshan Golden Bridge Biotechnology Co., Ltd.) at $37^{\circ} \mathrm{C}$ for $30 \mathrm{~min}$. Sections were stained with 3,3'-diaminobenzidine (Zhongshan Golden Bridge Biotechnology Co., Ltd.) for 5 min and restained with hematoxylin for $2 \mathrm{~min}$. Primary antibody was replaced by PBS in the negative controls. Positive CD31 expression was detected in the cytoplasm or membrane of vascular endothelial cells, which were used for marking and counting micro vessel density (MVD) (19). Blood vessel distribution was observed under a microscope at a magnification of x100. The area with the highest MVD was selected (hot spot) for the counting of microvascular numbers under a microscope at a magnification of $\mathrm{x} 400$ in three fields, the mean was recorded as the MVD of this tissue section. The emergence of brown-yellowish inside the cytoplasm was considered to indicate a positive result for VEGF cells. Positive STAT3 cells were visualized in the cytoplasm and/or nucleus with brown-yellowish coloration. VEGF and STAT3 expression levels were calculated as the ratio of immune positive area and the whole area. Three fields were randomly selected and observed at a magnification of $x 400$, and the mean was recorded as the VEGF and STAT3 expression levels of this tissue section.

Analysis of the DNA-binding activity of $N F-\kappa B$ p65. Nuclear protein was extracted using a Nuclear Extraction Kit (Active Motif, Carlsbad, CA, USA), following the manufacturer's instructions. A BCA Protein Assay Kit (Pierce; Thermo Fisher Scientific, Inc., Rockford, IL, USA) was used to detect the protein concentration. DNA-binding activity assay 

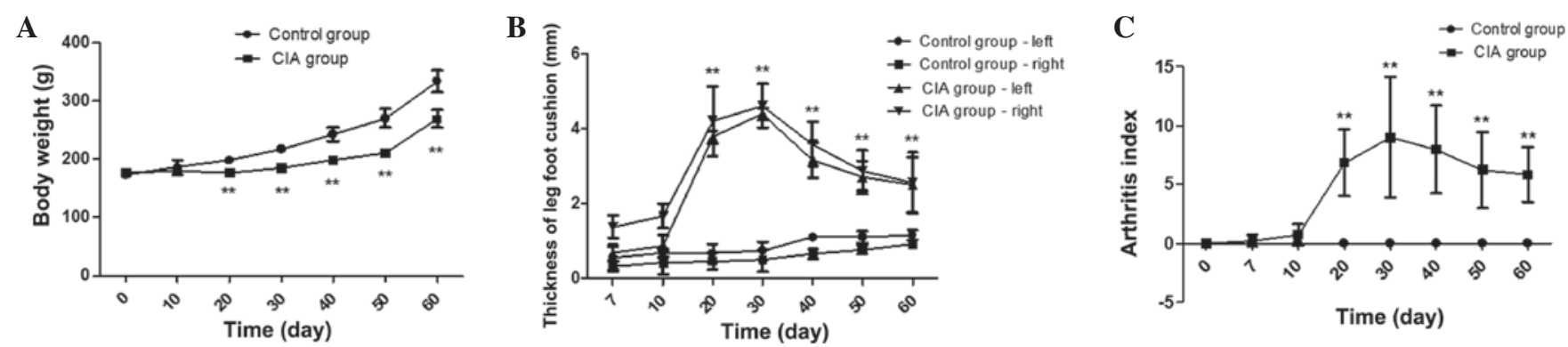

Figure 1. Body weight, joint swelling and arthritis index of rats in the control and CIA groups. (A) Body weight was obviously lower at days 20 , 30,40 , 50 and 60 in the CIA group rats compared with control group rats at the same period. (B) In the CIA group rats, the thickness of right and left leg foot cushion was increased at days 20,30, 40, 50 and 60 compared with the control group rats; (C) AI value was increased at days 20, 30 , 40, 50 and 60 in the CIA group compared with the control group rats. ${ }^{* *} \mathrm{P}<0.01$ vs. control group. CIA, collagen-induced arthritis.
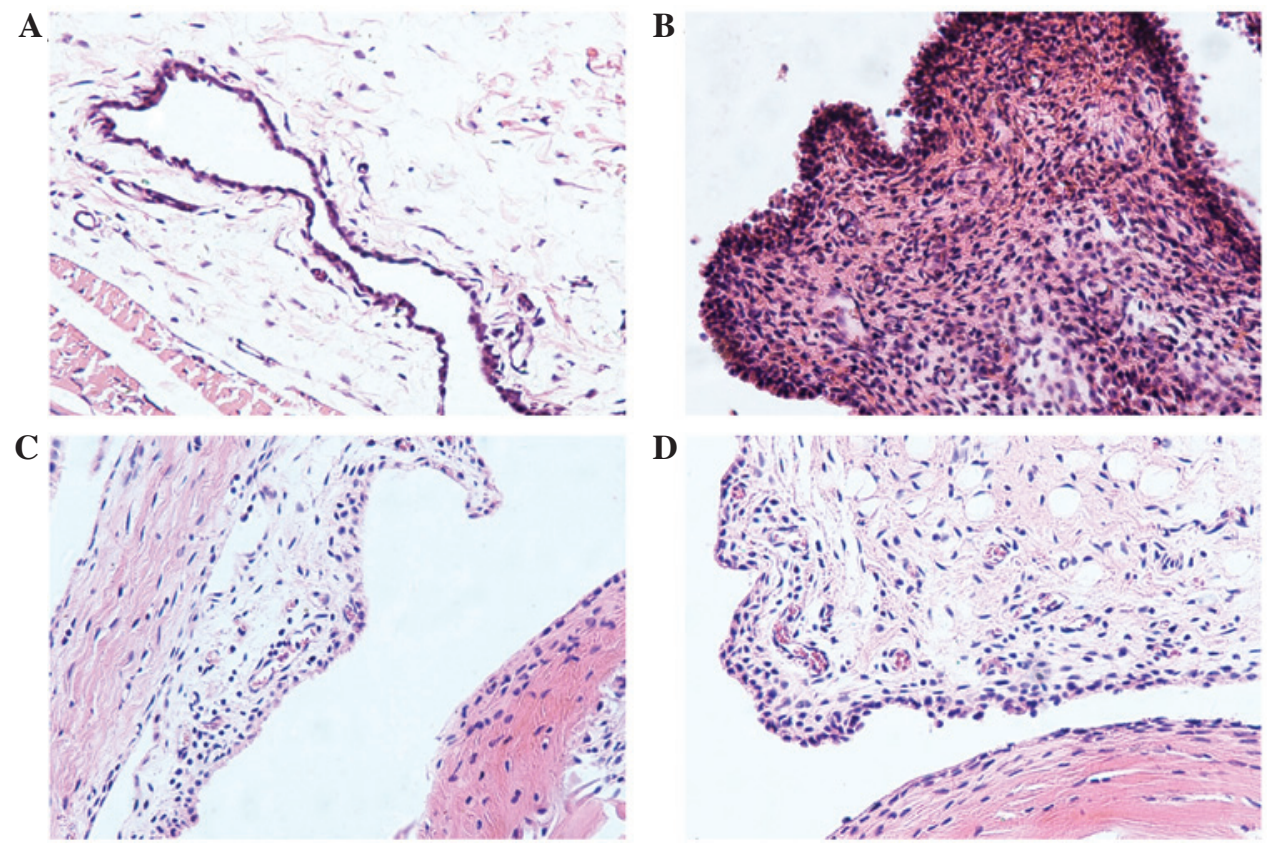

Figure 2. Hematoxylin-eosin staining of synovial tissues in various groups. (A) Synovial and joint in control group rats had no lesions, and synoviocytes were arranged regularly. (B) There were obvious pathological features, including synovial hyperplasia, inflammatory cell infiltration, pannus formation, cartilage and bone erosion in collagen-induced arthritis group rats. Pathological features were alleviated in the (C) Rhizoma Dioscoreae nipponicae and (D) tripterygium treated groups group. Magnification, x400.

for $\mathrm{NF}-\kappa \mathrm{B}$ p65 in nuclear proteins was determined using a TransAM Assay kit (cat. no. 40096; Active Motif). Briefly, $30 \mu \mathrm{l}$ binding buffer or binding buffer with $2 \mu \mathrm{l}$ specific oligonucleotides was added into each well. Subsequently, $20 \mu 1$ lysis buffer (Beyotime Institute of Biotechnology, Haimen, China) containing nuclear protein was incubated with connection buffer for $1 \mathrm{~h}$ at $25^{\circ} \mathrm{C}$ in the microplates. Subsequently, DNA oligonucleotide-bound protein was detected with anti-p65 $(1: 1,000)$ and secondary antibody $(1: 1,000)$. Successively, the chromogenic reagent and stop buffer were added into the each hole. Absorbance was detected at $450 \mathrm{~nm}$ using a microplate reader (Molecular Devices, Sunnyvale, CA, USA).

Statistical analysis. Statistical analysis was performed using SPSS software, version 11 (SPSS, Inc., Chicago, IL, USA). Data were expressed as the mean \pm standard deviation and analyzed using one-way analysis of variance and $\mathrm{Q}$ test. A value of $\mathrm{P}<0.05$ was considered to indicate a statistically significant difference.

\section{Results}

Changes in body weight, joint swelling and AI. Compared with the control group, rats in the CIA group exhibited symptoms including listlessness, slow response, dry, sparse hair, reduced activity and food intake. In addition, body weight was reduced by $10.78,14.95,18.20,22.04$ and $19.45 \%$ by days $20,30,40,50$ and 60 , respectively, in the CIA group rats compared with the control group rats at the same period $(\mathrm{P}<0.01)$ (Fig. 1A). In the CIA group rats, the thickness of right leg foot cushion was increased by 9.15-, 9.43-, 5.44-, 3.74- and 2.78-fold on days 20,30, 40, 50 and 60, respectively, compared with the control group rats $(\mathrm{P}<0.01)$ (Fig. 1B). Similarly, compared with the control group rats, the thickness of left leg foot cushion was increased by 5.56-, 5.56-, 2.87-, 2.43- and 2.16-fold on days 20, 30, 40, 50 and 60 in the CIA group rats $(\mathrm{P}<0.01)$ (Fig. 1B). Furthermore, there was no swelling of foot paw and AI value was 0 in blank group rats; however, AI value was significantly increased at days 20,30, 
Table I. MVD level and expression of VEGF and STAT3 in various groups.

\begin{tabular}{lccrr}
\hline Group & Dose $(\mathrm{mg} / \mathrm{kg} / \mathrm{day})$ & MVD $(\mathrm{n}=8)$ & VEGF $(\mathrm{n}=8)$ & STAT3 $(\mathrm{n}=8)$ \\
\hline Control & - & $3.00 \pm 0.71$ & $0.0014 \pm 0.0002$ & $0.448 \pm 0.354$ \\
CIA & - & $9.20 \pm 1.30^{\mathrm{a}}$ & $0.1167 \pm 0.0207^{\mathrm{a}}$ & $11.669 \pm 2.374^{\mathrm{a}}$ \\
RDN & 25 & $4.80 \pm 0.45^{\mathrm{b}}$ & $0.0452 \pm 0.0078^{\mathrm{b}}$ & $3.281 \pm 1.374^{\mathrm{b}}$ \\
TP & 12 & $5.00 \pm 0.82^{\mathrm{b}}$ & $0.0420 \pm 0.0057^{\mathrm{b}}$ & $2.836 \pm 1.625^{\mathrm{b}}$ \\
\hline
\end{tabular}

All the values expressed as means $\pm \mathrm{SD}$. ${ }^{\mathrm{a}} \mathrm{P}<0.01$ vs. control group, ${ }^{\mathrm{b}} \mathrm{P}<0.01$ vs. CIA group. MVD, microvessel density; VEGF, vascular endothelial growth factor; STAT3, signal transducer and activator of transcription 3; CIA, collagen induced-arthritis; RDN, rhizoma dioscoreae nipponicae; TP, tripterygium.

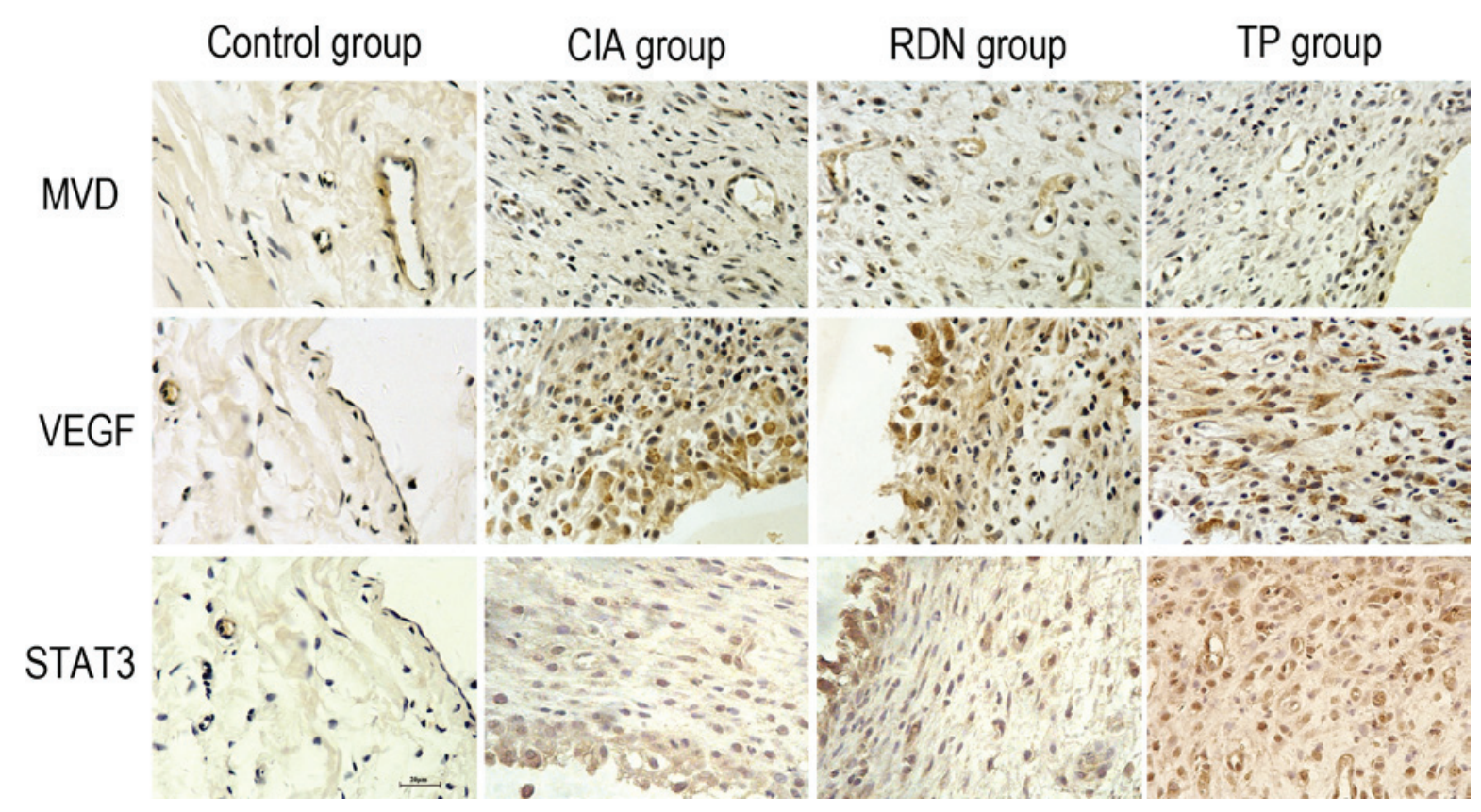

Figure 3. Immunohistochemical analysis of CD31, VEGF and STAT3 expression in the synovial tissues of the various groups. Compared with control group, the expression of CD31, VEGF and STAT3 were all increased in CIA group rat synovial tissue; however, total saponins of RDN or tripterygium appeared to inhibit the expression of these proteins (magnification, x400). CIA, collagen-induced arthritis; RDN, Rhizoma Dioscoreae nipponicae; TP, tripterygium; VEGF, vascular endothelial growth factor; STAT3, signal transducer and activator of transcription 3.

40, 50 and 60 compared with the control group rats $(\mathrm{P}<0.01)$ (Fig. 1C).

Histopathological changes of CIA rat synovial tissue after treatment. As shown in Fig. 2A, synovial and joint tissues in the control group rats exhibited no lesions, and synoviocytes were arranged regularly. However, there were obvious pathological features, including synovial hyperplasia, formation of pannus, infiltration of inflammatory cell, cartilage and bone erosion in the CIA group rats (Fig. 2B). Following treatment for 21 days, these pathological features were alleviated in RDN group and TP group compared with CIA group (Fig. 2C and D).

Detection of CD31, VEGF and STAT3 in CIA rat synovial tissue after treatment. Immunohistochemical analysis using anti-CD31 antibody showed that the number of CD31-labeled microvessels was larger, and the level of MVD was higher in the CIA group rat synovial tissue than the control group rats $(\mathrm{P}<0.01)$ (Table I; Fig. 3). Compared with CIA group, the level of MVD was reduced in RDN and TP group rat synovial tissues $(\mathrm{P}<0.01)$ (Table I; Fig. 3), while there was no significant difference between the RDN and TP groups (P>0.05) (Table I; Fig. 3).

The expression of VEGF and STAT3 protein was significantly increased in CIA group rat synovial tissue compared with the control group rats $(\mathrm{P}<0.01)$ (Table I; Fig. 3). However, the VEGF and STAT3 expression levels were lower in the RDN and TP group rat synovial tissues compared with the CIA group rats $(\mathrm{P}<0.01)$ (Table I; Fig. 3$)$, and no significant difference was detected between the RDN and TP groups (P>0.05) (Table I; Fig. 3).

DNA-binding activity of $N F-\kappa B$ p 65 in CIA rat synovial tissue after treatment. Compared with the control group, a significant increase $(\mathrm{P}<0.01)$ (Fig. 4) in the DNA-binding 


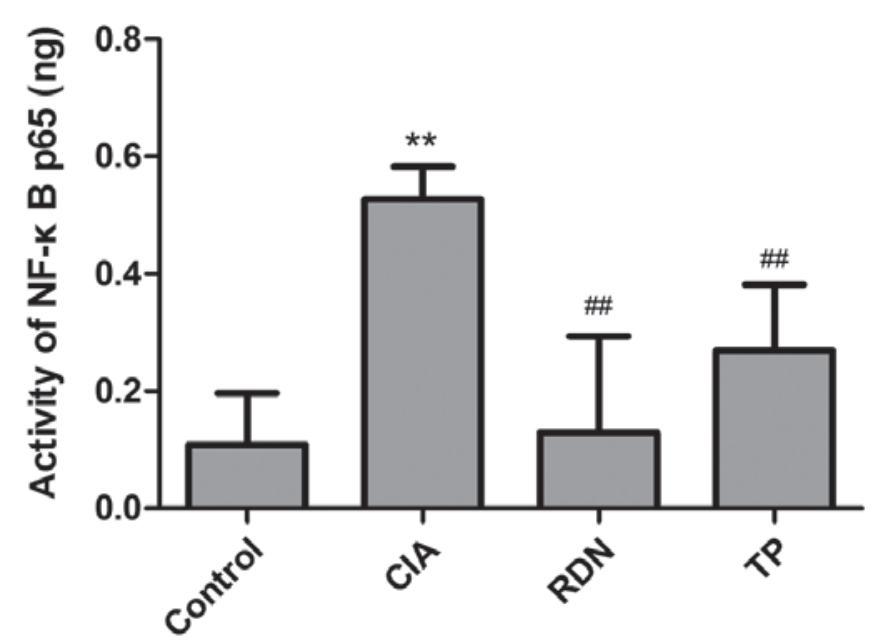

Figure 4. DNA-binding activity of NF- $\mathrm{B}$ of synovial tissues in various groups. Compared with the control group, a significant increase in the DNA-binding activity of NF- $\mathrm{B}$ p65 was observed in CIA group rat synovial tissue; however, the DNA-binding activity of NF- $\mathrm{B}$ p 65 was reduced in the RDN and TP groups. ${ }^{* *} \mathrm{P}<0.01$ vs. control group, ${ }^{\# \#} \mathrm{P}<0.01$ vs. CIA group. $\mathrm{NF}-\kappa \mathrm{B}$, nuclear factor- $\kappa \mathrm{B}$; CIA, collagen-induced arthritis; RDN, Rhizoma Dioscoreae nipponicae; TP, tripterygium.

activity of NF- $\mathrm{NB}$ p65 was observed in CIA group synovial tissue. After treatment with RDN and TP, the DNA-binding activity of NF- $\kappa \mathrm{B}$ p65 was reduced $(\mathrm{P}<0.01)$ (Fig. 4), while there was no significant difference between the RDN and TP groups ( $\mathrm{P}>0.05)$ (Fig. 4).

\section{Discussion}

RA is an autoimmune, systemic disease that may lead to the destruction of joints and subsequent disability (20). In the present study, we successfully established a CIA rat model to investigate the therapeutic potential of TSRDN. The results showed that TSRDN alleviated synovial hyperplasia, infiltration of inflammatory cells and the formation of pannus in CIA rats, as well as inhibiting the level of MVD, the expression of VEGF and STAT3, and the DNA-binding activity of $\mathrm{NF}-\kappa \mathrm{B}$ p 65 .

Angiogenesis involves the formation of new blood vessels from preexisting ones, and serves a crucial function in tissue development and repair (21). The formation of new microvessels within the synovium is a major feature of RA, which induced the development of pannus and resulted in the cartilage erosion and destruction, indicating that anti-angiogenesis may be an effective therapeutic strategy for RA (22). VEGF and its receptor play a vital role in angiogenesis by regulating endothelial cell proliferation, migration and lumen formation $(23,24)$. Previous studies have demonstrated that compared to healthy individuals, serum and synovial tissue VEGF concentrations were significantly elevated in patients with RA $(25,26)$. Furthermore, the expression levels of VEGF and its specific receptors, Flk-1 and Flt-1 were associated with arthritis severity and the degree of neovascularization (27). Similarly, the present results suggested that the level of MVD and the expression of VEGF protein were significantly increased in CIA rat synovial tissue, which was decreased after TSRDN or tripterygium treatment. In addition, TSRDN appeared to alleviate synovial hyperplasia and pannus formation, as indicated by observing the histological structure of synovial membrane tissues. Tripterygium is a commonly used TCM for the treatment of RA (28). The presents results indicated that VEGF may be involved in the occurrence and development of CIA by regulating angiogenesis, and TSRDN may be a potential therapeutic drug for CIA.

To further investigate the mechanism of TSRDN in angiogenesis and RA, we detected the expression levels of STAT3 and NF- $\kappa$ B. The expression levels of various cytokines are known to be significantly increased in RA synovial tissues, and the majority of these are regulated via the JAK-STAT signaling pathway (7). Furthermore, the pathological process of RA may be improved by blocking JAK-STAT pathway $(6,29)$. Shouda et al $(30)$ demonstrated that removing the functional domain of STAT3 attenuated CIA, and the hyperactivation of STAT3 may result in the spontaneous development of autoimmune arthritis (31). Furthermore, Krause et al (32) proposed a mechanism by which STAT3 may promote the pathogenesis of RA by suppressing the apoptosis of synovial fibroblasts. STAT3 plays a crucial regulatory role in angiogenesis by upregulating VEGF expression $(9,33,34)$. Notably, we demonstrated that the expression of STAT3 protein was significantly increased in CIA rat synovial tissue, and decreased following TSRDN treatment, indicating that TSRDN may inhibit the pathogenesis of CIA by downregulating STAT3 expression.

In addition, $N F-\kappa B$, a protein with the function of promoting gene transcription, has been shown to actively participate in pathological processes such as joint inflammation (35). NF- $\kappa \mathrm{B}$ has been shown to be widely expressed in RA synovial cells (36), which is consistent with the present results. Previous studies have shown that $\mathrm{NF}-\kappa \mathrm{B}$ may be involved in regulating angiogenesis (37), and that inhibiting the activity of $\mathrm{NF}-\kappa \mathrm{B}$ in pancreatic cancer may prevent the formation of new blood vessels (38). The present study showed that the DNA-binding activity of NF- $\kappa \mathrm{B}$ p65 could be inhibited by TSRDN. Therefore, we speculated that $\mathrm{NF}-\kappa \mathrm{B}$ was involved in the inhibiting effect of TSRDN on CIA, by regulating angiogenesis.

In conclusion, the present results suggested that CIA rat synovial tissue had a large number of new blood vessels, which was consistent with increased expression of VEGF protein; however, TSRDN could inhibit this phenomenon. We speculated that TSRDN might prevent angiogenesis by inhibiting the expression of STAT3 and the DNA-binding activity of $N F-\kappa B$ p 65 , thereby played a positive role in improving CIA. TSRDN may be a potential therapeutic drug for CIA, and VEGF may be involved in the development of CIA by regulating angiogenesis. Furthermore, TSRDN could inhibit the pathogenesis of CIA by downregulating STAT3 expression. $\mathrm{NF}-\kappa \mathrm{B}$ was involved in the inhibiting effect of TSRDN on CIA.

\section{Acknowledgements}

This study was supported by the National Natural Science Foundation of China (grant no. 30873420). 


\section{References}

1. Harris ED Jr: Rheumatoid arthritis. Pathophysiology and implications for therapy. N Engl J Med 322: 1277-1289, 1990.

2. Feldmann M, Brennan FM and Maini RN: Role of cytokines in rheumatoid arthritis. Annu Rev Immunol 14: 397-440, 1996.

3. Gabriel SE: The epidemiology of rheumatoid arthritis. Rheum Dis Clin North Am 27: 269-281, 2001.

4. McInnes IB and Schett G: The pathogenesis of rheumatoid arthritis. N Eng J Med 365: 2205-2219, 2011.

5. Marrelli A, Cipriani P, Liakouli V, Carubbi F, Perricone C, Perricone R and Giacomelli R: Angiogenesis in rheumatoid arthritis: A disease specific process or a common response to chronic inflammation? Autoimmun Rev 10: 595-598, 2011.

6. Fava RA, Olsen NJ, Spencer-Green G, Yeo KT, Yeo TK, Berse B, Jackman RW, Senger DR, Dvorak HF and Brown LF: Vascular permeability factor/endothelial growth factor (VPF/VEGF): Accumulation and expression in human synovial fluids and rheumatoid synovial tissue. J Exp Med 180: 341-346, 1994.

7. Walker JG and Smith MD: The Jak-STAT pathway in rheumatoid arthritis. J Rheumatol 32: 1650-1653, 2005.

8. Tak PP, Gerlag DM, Aupperle KR, van de Geest DA, Overbeek M, Bennett BL, Boyle DL, Manning AM and Firestein GS: Inhibitor of nuclear factor kappaB kinase beta is a key regulator of synovial inflammation. Arthritis Rheum 44: 1897-1907, 2001

9. Chen Z and Han ZC: STAT3: A critical transcription activator in angiogenesis. Med Res Rev 28: 185-200, 2008.

10. Karin M: Nuclear factor-kappaB in cancer development and progression. Nature 441: 431-436, 2006.

11. Smolen JS, Aletaha D, Koeller M, Weisman MH and Emery P: New therapies for treatment of rheumatoid arthritis. Lancet 370: 1861-1874, 2007.

12. Yan W, Ji L, Hang S and Shun Y: New ionic liquid-based preparative method for diosgenin from Rhizoma dioscoreae nipponicae. Pharmacogn Mag 9: 250-254, 2013.

13. Wang TS, Liang SJ, Lii CK and Liu SY: Protective effect of water yam (Dioscorea alata L.) extract on the copper driven fenton reaction and X-ray induced DNA damage in vitro. Phytother Res 18: 325-328, 2004.

14. Jeon JR, Lee JS, Lee CH, Kim JY, Kim SD and Nam DH: Effect of ethanol extract of dried Chinese yam (Dioscorea batatas) flour containing dioscin on gastrointestinal function in rat model. Arch Pharm Res 29: 348-353, 2006.

15. Yao L, Dong W, Lu F and Liu S: An improved acute gouty arthritis rat model and therapeutic effect of rhizoma dioscoreae nipponicae on acute gouty arthritis based on the protein-chip methods. Am J Chin Med 40: 121-134, 2012.

16. Wooley PH, Luthra HS, Stuart JM and David CS: Type II collagen-induced arthritis in mice. I. Major histocompatibility complex (I region) linkage and antibody correlates. J Exp Med 154: 688-700, 1981.

17. Cremer M: Type II collagen-induced arthritis in rats. In: Handbook of Animal Models for the Rheumatic Diseases Greenwald RA and Diamond HS (eds). Vol 1. CRC Press, Boca Raton, FL, pp17-27, 1988.

18. Welles WL and Battisto JR: Suppression of adjuvant arthritis by antibodies specific for collagen type II. Immunol Commun 10: 673-685, 1981

19. Anic GM, Thompson RC, Nabors LB, Olson JJ, Browning JE, Madden MH, Murtagh FR, Forsyth PA and Egan KM An exploratory analysis of common genetic variants in the vitamin D pathway including genome-wide associated variants in relation to glioma risk and outcome. Cancer Causes Control 23: 1443-1449, 2012

20. Yamanishi Y, Boyle DL, Pinkoski MJ, Mahboubi A, Lin T, Han Z, Zvaifler NJ, Green DR and Firestein GS: Regulation of joint destruction and inflammation by $\mathrm{p} 53$ in collagen-induced arthritis. Am J Pathol 160: 123-130, 2002.
21. Ferrara N and Kerbel RS: Angiogenesis as a therapeutic target. Nature 438: 967-974, 2005.

22. Semerano L, Clavel G, Assier E, Denys A and Boissier MC Blood vessels, a potential therapeutic target in rheumatoid arthritis? Joint Bone Spine 78: 118-123, 2011.

23. Ferrara N: Role of vascular endothelial growth factor in the regulation of angiogenesis. Kidney Int 56: 794-814, 1999.

24. Carrato A, Gallego-Plazas J and Guillen-Ponce C: Anti-VEGF therapy: A new approach to colorectal cancer therapy. Expert Rev Anticancer Ther 6: 1385-1396, 2006.

25. Lee SS, Joo YS, Kim WU, Min DJ, Min JK, Park SH, Cho CS and Kim HY: Vascular endothelial growth factor levels in the serum and synovial fluid of patients with rheumatoid arthritis. Clin Exp Rheumatol 19: 321-324, 2001.

26. Ballara S, Taylor PC, Reusch P, Marmé D, Feldmann M, Maini RN and Paleolog EM: Raised serum vascular endothelial growth factor levels are associated with destructive change in inflammatory arthritis. Arthritis Rheum 44: 2055-2064, 2001.

27. Lu J, Kasama T, Kobayashi K, Yoda Y, Shiozawa F, Hanyuda M, Negishi M, Ide H and Adachi M: Vascular endothelial growth factor expression and regulation of murine collagen-induced arthritis. J Immunol 164: 5922-5927, 2000.

28. Tao X, Cush JJ, Garret M and Lipsky PE: A phase I study of ethyl acetate extract of the chinese antirheumatic herb Tripterygium wilfordii hook $\mathrm{F}$ in rheumatoid arthritis. J Rheumatol 28: 2160-2167, 2001.

29. Walker JG, Ahern MJ, Coleman M, Weedon H, Papangelis V, Beroukas D, Roberts-Thomson PJ and Smith MD: Changes in synovial tissue Jak-STAT expression in rheumatoid arthritis in response to successful DMARD treatment. Ann Rheum Dis 65: 1558-1564, 2006.

30. Shouda T, Yoshida T, Hanada T, Wakioka T, Oishi M, Miyoshi K, Komiya S, Kosai K, Hanakawa Y, Hashimoto K, et al: Induction of the cytokine signal regulator SOCS3/CIS3 as a therapeutic strategy for treating inflammatory arthritis. J Clin Invest 108: 1781-1788, 2001

31. Atsumi T, Ishihara K, Kamimura D, Ikushima H, Ohtani T, Hirota S, Kobayashi H, Park SJ, Saeki Y, Kitamura Y and Hirano T: A point mutation of Tyr-759 in interleukin 6 family cytokine receptor subunit gp130 causes autoimmune arthritis. J Exp Med 196: 979-990, 2002.

32. Krause A, Scaletta N, Ji JD and Ivashkiv LB: Rheumatoid arthritis synoviocyte survival is dependent on Stat3. J Immunol 169: 6610-6616, 2002.

33. Niu G, Wright KL, Huang M, Song L, Haura E, Turkson J, Zhang S, Wang T, Sinibaldi D, Coppola D, et al: Constitutive Stat 3 activity up-regulates VEGF expression and tumor angiogenesis. Oncogene 21: 2000-2008, 2002.

34. Wei LH, Kuo ML, Chen CA, Chou CH, Lai KB, Lee CN and Hsieh CY: Interleukin-6 promotes cervical tumor growth by VEGF-dependent angiogenesis via a STAT3 pathway. Oncogene 22: 1517-1527, 2003.

35. Makarov SS: NF-kappaB in rheumatoid arthritis: A pivotal regulator of inflammation, hyperplasia, and tissue destruction. Arthritis Res 3: 200-206, 2001.

36. Roman-Blas JA and Jimenez SA: NF-kappaB as a potential therapeutic target in osteoarthritis and rheumatoid arthritis. Osteoarthritis Cartilage 14: 839-848, 2006.

37. De Martin R, Hoeth M, Hofer-Warbinek R and Schmid JA: The transcription factor NF-kappa B and the regulation of vascular cell function. Arterioscler Thromb Vasc Biol 20: E83-E88, 2000.

38. Xiong HQ, Abbruzzese JL, Lin E, Wang L, Zheng L and Xie K: NF-kappaB activity blockade impairs the angiogenic potential of human pancreatic cancer cells. Int J Cancer 108: 181-188, 2004. 